\title{
Social Welfare and Integrated \\ Resource Management ${ }^{1}$
}

\section{DILLARD H. GATES}

Director, Rangeland Resources Program, Oregon State University, Corvallis.

\section{Highlight}

Resource management decisions cannot be properly made based upon single use but must give full consideration to altcrnative uses or combinations of uses. The impact of uses upon resources must be evaluated. The soundness of management decisions must be evaluated on the basis of their impact upon human welfare. A philosophy of integrated resource management will reflect concern for both resources and people.

The dependence of man upon resources is legend.

The demands placed upon wildland resources by a growing, mobile, affluent and leisure-time oriented population is a legend in our time. Despite accelerating demands upon wildland resources, we do not understand the complex interactions between resources and man. We have limited knowledge and a partial understanding of the impact of various land management decisions upon resources. In many cases, decisions may have been made and forgotten without monitoring or evaluating either their direct or side effects. Only in comparatively recent times have we become particularly concerned about the full impact of man's actions upon resources. Concern for the lack of understanding of the impact of resources and resource use upon man is of even a more recent vintage. In fact, it is just emerging.

An increasing, but still limited, part of the population now realizes that wildland resources are limited. This realization alone has placed additional stress on an already stressed human environment. We now worry not only about how to acquire additional resources for human use but also about how our use of resources adds to their scar-

${ }^{1}$ Received for publication April 24, 1972. city or contributes to their depletion. We (at least some of us) now realize that man must "make do" with what he now has and that what he now has is both limited (Planet Earth) and limiting insofar as human welfare is concerned.

Although resources are limited the seemingly limitless population growth makes increasing dcmands on resources. Therefore, it is imperative that land use decisions or schemes of management optimize production of goods and values from wildland resources over the long run. We can no longer afford expedient short-run economic optimization.

Goods and values derived from wildland resources are assumed to be necessary or desirable from the standpoint of the social welfare of man. A nation-wide policy of integrated resource management, embracing both public and private lands, is needed to achieve the goal of optimizing production of goods and values from wildland resources over the long run.

D. A. Smith ${ }^{2}$ defined integrated resource management as, "The application of management strategies to achieve the maximum output from the optimized use of natural resources of a specific area for the benefit of a referent-group and its successors." This definition provides a framework within which to achieve the public goal for resource management.

Our representative form of government contains the mechanisms to translate public attitudes into goals as well as action to accomplish these goals. Individuals and groups set society's goals by articulating their desires and through the ballot box. Society's goals

${ }^{2}$ Master of Forestry thesis, University of British Columbia, 1969. should provide the conceptual framework for planning, establishment of objectives and their implementation.

Some goals for resource use have been identified through legislation such as the Multiple Use, Environmental Protection and Environmental Quality Acts. Many individuals and/or groups may not fully support either the legislation or the goals. We assume these goals do reflect the attitude of the broad public today on matters of resource management and environmental quality.

Expressed goals, no matter how noble, are merely rhetoric until supported by objectives designed to accomplish the goals and implement objectives. For example: a goal set by society may be to enhance and protect the environmental quality of rangelands. To reach this goal, certain specific things must be done-that is, objectives must be set. An objective may be to restore vegetation to its natural state on specific areas. However, this objective is still meaningless unless implemented. This means planning, funds, and manpower. Thus, the planning process for integrated resource management must embrace setting of goals, establishment of objectives and implementation of actions necessary to accomplish the objectives. No plan is complete unless it includes methods for implementation.

The resource manager generally gets into the planning loop when objectives are established or the implementation of action to accomplish objectives that have been set by others. The proper point to insert resource management expertise into the planning process is a moot question. I feel it should be much sooner. However, significant resource manager inputs generally follow broad policy decisions or setting of goals. This procedure frequently places the resource manager in the difficult position of being asked-required-expectedor ordered to carry out or develop resource treatments or management 
schemes not compatible with ecological characteristics of wildland resources. In other words, the resource manager may be committed to action as a result of decisions made by others who had less than the best possible knowledge and understanding of the problem.

We should recognize that resource managers do not always utilize fully all information available in their resource management decision-making processes. This is especially true when the decision maker is strongly single disciplineoriented or when through ignorance he fails to involve other legitimate disciplines into the decision-making process.

In most cases today, resource decisions cannot be based upon single disciplines or single use but must give full consideration to alternatives or combinations of use. In so doing, the impact of various uses or combination of uses upon both resources and resource users must be understood and evaluated. Results of these evaluations become a part of the decision-making processes.

Tragically, all the information now available sometimes has little impact upon the human characteristics of seeing only one side of a problem or presenting only one viewpoint. In fact, the great amount of information (not always facts) available to decision makers may actually ease the management decisions without fully exploring all facets of a problem.

Objectivity is still a rare commodity. However, it can be increased and strengthened by insisting that resource information is factual and by taking an interdisciplinary approach to integrated resource management. An interdisciplinary approach to problem solving will add not only credibility but acceptance to resource management decisions.

Accelerating demands on rangelands require an interdisciplinary approach to resource problems. Paradoxical, these very demands from an expanding and concerned society may force the interdisciplinary approach to integrated resource management. In the long run, rangeland resources may be "saved" by forces or activities which at first appeared to be, and in many cases probably were, destructive. What at first appeared to be our dilemma would be our salvation. Silent Spring and many so-called Doom's Day ecologists have caused us to look more closely at what we wore doing with our resources and ourselves.

Integrated resource management has significant social implication when related to management and use of resources by and for man. Contrary to the viewpoint of the traditional conservationist or preservationist, resources are not managed for the sake of resources but for people. Thus, integrated resource management includes an increasingly important social dimension that may be difficult for some resource managers to recognize, appreciate, or deal with effectively.

In general, resource managers have been trained to manage resources. Management decisions were, or are, made primarily upon the basis of their impact upon resources. Traditionally the qualified resource manager had at least a working understanding of the response of rangeland resources to given specific treatments. $\mathrm{He}$ was little concerned about the social implications of resource management decisions. For too long, too many resource managers have operated under the false premise that both their authority and responsibility stopped at a given boundary.

These procedures are no longer acceptable. The resource manager today must make his decision with full consideration of its social implications. He must understand resources. He must understand the impact of people upon resources. Just as importantly, he must be sensitive to the impact of resources on people. The rangeland resource manager must recognize the social implications implicit in many biological phenomena. Most of us consider ourselves biologists. We must recognize that neither biology nor sociology is a separate and distinct science. Resource management decisions must be made only following a full evaluation of their impact on human welfare. (In fact, this is a good basis for evaluating most decisions.)

A multidisciplinary approach to resource decisions is required to assure adequate understanding and treatment of capabilities and limitations of resources, needs and desires of people, and the social environment in which the decision is made. The multidisciplinary approach involves more than a range man, a forester, and a wildlife man having a cup of coffee together. It involves all concerned disciplines really working together. 'Ihus, if we are actually managing resources for man, can the social scientist be omitted? This may appear to be a cumbersome approach, but in the final analysis, it will provide a mechanism for expertise in all concerned disciplines to be appropriately applied to problems of resource management.

\section{Summary}

(1) We must understand the resource and people we are trying to manage.

(2) Resources are managed for people. Therefore, resource decisions must reflect a concern for human welfare.

(3) A multidisciplinary approach is required to provide understanding, credibility, and acceptance of management decisions.

(4) The concept of integrated resource management embraces the resources, the people, and their interactions.

Lom Longmont Seed Co. We Buy \& Sell Western Range Grass \& Legume Seeds

CONFRONT US with your RANGE PROBLEMS: phone: $303+776-1320$ LONGMONT, COLORADO 80501 